\section{Migrations are of all times}

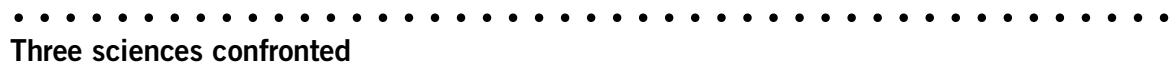

'Past human migrations in East Asia. Matching archeology, linguistics and genetics', edited by Alicia Sanchez-Mazas, Roger Blench, Malcolm D Ross, llia Peiros and Marie Lin.

ISBN13: 978-0-415-39923-4

ISBN13: 978-0-203-92678-9

Published by Routledge, Taylor \& Francis Group, 2008, hardcover.

...........

Frank Roels

n.

European Journal of Human Genetics (2010) 18, 262-263; doi:10.1038/ejhg.2009.149

$\mathrm{T}$ his multiauthored volume of 456 pages is contributed by geneticists, archeologists, and linguists. All try to describe past human migrations that took place over millenia before written documents were available.

Each author uses the approach specific for his or her individual discipline, and the first and excellent chapter on methodoloy written by the editors underlines that data collection, precision, extrapolation, and speculation vary a lot. In addition, the reader should not expect that conclusions are compared systematically between disciplines and 'integrated'; in the best scenario they provide independent support for hypotheses about the past. However, often they do not.

This is illustrated by the contribution of Jing Yuan et al. Their photograph of an excavation pit shows a carriage and the skeletons of two horses put to it. Burial pits with horses have been found by the dozens in the province of Henan, China. The authors say these were probably sacrifices; but why not propose that important people needed their horses in the hereafter? Somewhere is also an inscription saying 'the king fed horses in the stables'. Obviously, horses were very important at that period. That was 3300-3050 BP, as concluded from radiocarbon dating. One mtDNA sequence corresponds to Equus caballus przewalskii, others to modern horses. However, remarkably no horses were at all found a few hundred years earlier (3600$3400 \mathrm{BP}$ ); in contrast some were in Shaanxi province around $4000 \mathrm{BP}$. Although remains of domesticated dogs go back as far as 10500-9700 BP, and pigs around 6000 BP. The authors conclude that horse domestication was imported into Henan during the later Shang dynasty, that is by migration from elsewhere. Whether linguistics and genetics (mtDNA and $\mathrm{Y}$ chromosome variation) match archeological data is discussed in the next chapter by Roger Blench, and is answered with a careful no: too few hard facts, and too easy speculation by some earlier authors.

On the other hand, convergence between conclusions of the three disciplines is not necessarily to be expected: if language shifts are associated with an evolution in economy, that is foraging to agriculture (well reflected in archeology), DNA will not change. Vice versa, a given gene can diffuse through intermarriage without true population migration. Geographic barriers (but not culture and language) will cause gene discontinuities: islands can explain genetic heterogeneity and can demarcate possible migration routes. Languages can transform and diversify in many ways and often it is an open question which relationship if any with migration or genetics might be extracted.

The editors themselves describe the limitations of the methods in all disciplines. Geneticists, for exemple, when constructing a phylogenetic tree imply a constant speed of genetic divergence, which is an approximation. The clock is then calibrated against absolute dates of fossiles of common ancestors of humans and chimpanzees. However, apes exhibit a much higher level of intraspecific divergence than humans. In fact, the rate of evolution of gene frequencies depends do not correspond to identifiable events in population history. Trees based on a mtDNA marker do not fit with those based on the $\mathrm{Y}$ chromosome (172000 years vs 59000 years). A promising approach uses on population size. Genetic tree nodes often computer simulation of several scenarios starting from arbitrary choices of parameters and then favours the model that best explains real data. Another critique is the 'highly unscientific' nature of the samples analysed: 'West or South Africans' are compared to 'Caucasians', a term that is a euphemism for 'white race', nowadays unacceptable, or a handful of populations samples from 'Africans' are supposed to represent the huge ethnic and linguistic diversity in this big continent. 'Non-Africans' even has been used - nonsensical.

Linguistics is under a more severe scrutiny still. Reconstruction of an extinct or theoretical proto-language or archaic is based on the assumption, among others, that basic vocabulary changes at a constant rate and can lead to dating. The editors give a ludicrous example where this resulted in archaic cropnames dated some millenia before the start of agriculture in that region (according to archeology). Linguists use the notion of phyla of languages that are related because they developed from one archaic language. A classical example is Altaic, taken to include Turkic, Mongolic, Tingustic, and KoreanJaponic. However, loanwords introduced by interaction of two languages is of course no argument for a common origin. Koreans were probably in contact with Japanese over an extended period explaining language similarities. One procedure is to look for parallel forms in words, such as morphemes of three or more syllables. But in mainland SouthEast Asia languages tend to have monosyllabic morphemes, so that correspondences of sound are the only evidence of phylic relationships. On the mainland again, longstanding and intense contact between populations do not reflect linguistic phylogeny. The very long periods over which phyla have supposedly developed, for example, 8000 years, make collection of sufficient data impossible. Even ancient written texts are not always helpful, as shown by Sanskrit of which there is no evidence it was ever spoken. Hence, it should not be confused with the reconstructed Proto-Indo-Aryan assumed to be the mother of our European languages.

Archeology seems more reliable; but interpreting can be flawed by teleological nationalistic feelings that hijack ancient cultures as precursors of the 20th century states - though so many millenia ago there must have been dead ends too. Winnetou, Mayas, or Aztecs were no precursors of President Obama's United States nor were the Neanderthalers of Homo sapiens (although recent data 
suggest we have underestimated their intelligence).

\section{OUT OF TAIWAN TO POLYNESIA}

Many data indicate that neolithic people from Taiwan travelled overseas southbound to the Batanes Islands, then Luzon, that is the northern Philippines. From there they sailed eastward and reached as far as Melanesia, Lapita, and Polynesia, Samoa as well as to eastern Indonesia. This happened in several migratory phases between $3000 \mathrm{BC}$ and $1200 \mathrm{AD}$ (New Zealand). Taking the distance of nearly $10000 \mathrm{~km}$, an average migration 'speed' of $18.5 \mathrm{~km}$ per year can be calculated (Peter Bellwood).

The archeological evidence of the first stage goes as follows: pottery found in caves and rock shelters on the islands Batan and Itbayat between Taiwan and the Philippines and dated 2000-1250-900 BC resembles very strongly that of Taiwan dated 2200 BC. Stronger still, artefacts in nephrite stone must have been imported from the nephrite mine on Taiwan. The domesticated pigs found also could not have a Batanes origin. On Batan there are no human remains older than the ceramic period, so there first inhabitants must have come from Taiwan (in contrast on Luzon a culture of hunterers goes back $25000 \mathrm{BP})$. The drive for the migration waves is postulated to have been population growth on islands with finite resources.

The linguistic evidence is the following. Original languages spoken in Taiwan, the North Philippines, western Sumatra, central Sulawesi, Flores, New Guinea, and Samoa have many words in common with small differences in sound (pronunciation). So Formosan and Malayo-Polynesian form a family of Austronesion languages. The subset of Oceanic reaches as far as New Zealand, Tahiti, and Easter Island. Does that mean that the communities speaking them have a common origin? Not necessarily, adoption is possible by a community originally speaking some other language. In the area are a few examples of such a 'shift', documented by oral stories, or by a change in pronunciation (a well-known example of the latter is the English spoken in India). Papuas spoke their own languages before the Austronesion arrived. However, many islands of Polynesia were still inhabited when Austronesion made their appearance. Austronesian should not be confused with Pidgin-English, which is formed in situations of strong social inequity.

\section{How do linguists arrive at a genealogical tree?}

When innovations are shared by a group of, for example, five languages, then it is most likely that they developed from a single ancestor (where these innovations occurred). An innovation is a change of a vowel or consonant in a single language compared with all other languages of its group (=languages with large similarities of vocabulary and grammar). Examples of innovations given by Ross are disappearance of $S$ or $\mathrm{T}$; OO becomes OW; L becomes $\mathrm{R}$, or $\mathrm{R}$ becomes L. The reconstructed proto-language has features without these innovations. These models imply indeed a one-way development; the alternative (the change going the other way) is each time considered but estimated less likely. Innovations are also assumed to take a considerable time that a population stayed together.

Using these methods, Ross draws a genealogical tree starting from Proto-Austronesian, from which nine groups of Formosan first developed, as well as the Proto-Malayo-Polynesian that further produced 20-25 language groups and Proto-Central-Eastern. The latter developed into Central Eastern and Eastern Malayo-Polynesian and Proto-Oceanic. It is clear this inheritance happened over millenia, and simultaneously moved geographically southward and eastward. Timing however must come from archeology, and it is a theory, well argued but disputed on several points by other linguists. The relationship with Old-Chinese (Sino-Tibetan family) is much debated (George van Driem, Starostin, and many others).

The genetic evidence of migration is easier to understand for readers of the EJHG. Motives of mtDNA in living inhabitants of Taiwan as well as from prehistoric skeletons (Erika Hagelberg et al) are also found in populations of the Philippines, Moluccas, Indonesia, including coastal New Guinea but not in highlanders who still speak older Papuan languages, and in skeletons on far away Easter Island. In particular, the haplogroup B4ala is shared by Taiwanese and Polynesians.
The inhabitants of Taiwan, who immigrated from mainland China after World War II or a few centuries earlier, and who speak mainland Chinese (Han), have different mtDNA haplogroups, as do Vietnamese. Although it is unclear why in the three-principal component analysis, three groups from southern Taiwan are farther away form Luzon than South Vietnam (Jean Trejaut). What became known as 'the Polynesian motive' encompasses a $9 \mathrm{bp}$ deletion of the tandem repeat CCCCCTCTA, and four substitutions at positions $16189,16217,16247$, and 16261. They were found in present day Tahitians, and prehistoric Hawaii. Y chromosome deletions, on the other hand, are common to Polynesians and Melanisians. HLA variants show a relationship between Taiwanese, Han Chinese, Papua New Guinea, and Samoa - and are virtually absent from Europeans and Africans. Indonesia, Fuji, and Tonga are complicating the picture as does the Polynesionan motive found in inhabitants of Madagascar, whose language also belongs to the Austronesion family. How did they migrate?

In terms of time scales, coalescence times for Taiwanese and Polynesian haplogroups, as given by Trejaut, are 7900-13 200 years ago. I find those curiously different from archeological migration schemes (see above). Might this mean that mtDNA actually mutates much faster than commonly assumed, or is my reasoning wrong?

I have selected a few chapters, and so I did injustice to many other contributors, such as the work using GM (IgG immunoglobulin) polymorphism, by Alicia Sanchez-Mazas et al.

Although the volume was inspired by a 2004 conference, references are updated to 2007. It is completed by a detailed alphabetical index of 12 pages.

This is a fascinating but also a difficult book, because it confronts us with other sciences and very different techniques and ways of reasoning, when trying to study the same phenomenon, that is migrations that took place long before men made written accounts

\section{CONFLICT OF INTEREST}

The authors declare no conflict of interest.

Frank Roels is at the Department of Pathology, Ghent University Hospital, Ghent, Belgium E-mail: frank.roles@ugent.be 